\title{
New tools in minimal invasive aortic valve surgery: case report
}

\author{
Sofia Martin-Suarez ${ }^{1}$, Carlo Mariani ${ }^{1}$, Giacomo Murana ${ }^{1}$, Marianna Berardi $^{1}$, Marta Agulli $^{2}$, Savini Carlo ${ }^{1}$, \\ Davide Pacini ${ }^{1}$ \\ ${ }^{1}$ Cardiac Surgery Unit, Cardio-Thorac-Vascular Department, S. Orsola Hospital, ALMA Mater Studiorum University of Bologna, Bologna, Italy; \\ ${ }^{2}$ Cardio Anesthesia Unit, Cardio-Thorac-Vascular Department, S. Orsola Hospital, ALMA Mater Studiorum University of Bologna, Bologna, Italy \\ Correspondence to: Sofia Martin-Suarez, MD, PhD. Cardiac Surgery Unit, Cardio-Thorac-Vascular Department, S. Orsola Hospital, ALMA Mater \\ Studiorum University of Bologna, Via Massarenti n.9, 40138 Bologna, Italy. Email: docsofi74@hotmail.com; sofia.martinsuarez@aosp.bo.it.
}

\begin{abstract}
Minimal invasive aortic valve replacement (MI-AVR) is turning a routine surgical procedure, but still, many surgeons are reluctant because of perception of some technical difficulties like the annular suture placement and the legature. We present the surgical case of a MI-AVR by using novel suturing and knotting device that could facilitate surgery and diminish technical difficulties. This is the case of a 65 -year-old female patient with a pathologic bicuspid aortic valve, with stenosis and prevalent regurgitation. The patient was symptomatic for dyspnea (NYHA Class II) and referred to surgery for AVR, and after obtaining informed consent, we performed MI-AVR through upper hemisternotomy (UHS) by using two new surgical devices, particularly designed for minimal invasive surgery. The first device is composed by two handpieces: one is known as $\mathrm{RAM}^{\circledR}$, and it allows the passage of the suture, with the pledget in the ventricular side, through the native aortic valve anulus after the cusps have been removed and decalcification performed. Double "U" stitches are homogeneously and symmetrically placed. The second element, called SEW-EASY ${ }^{\circledR}$ is used to pass equally the double needle suture through the sewing ring of the valvular prosthesis. To conclude, in this case we have also utilized a second device, a knotting one, known as COR-KNOT ${ }^{\circledR}$, giving rise to a quick and efficient suture ligature. Postoperative course was uneventful and the patient was on good conditions after 1 year of follow-up. The present case highlights the need and evolution of technology aimed to improve, simplify and increase safety in minimal invasive surgery.
\end{abstract}

Keywords: Minimal invasive; aortic valve replacement (AVR); tools; innovations; case report

Received: 05 May 2020; Accepted: 04 December 2020; Published: 20 July 2022.

doi: 10.21037 /jovs-20-126

View this article at: http://dx.doi.org/10.21037/jovs-20-126

\section{Introduction}

In the last decades, medical community has witnessed a significant rise of the incidence of aortic valve pathologies, mostly degenerative, requiring replacement therapy. Due to an increase in life expectancy, the surgical and cardiology teams must afford an older and full of comorbidities population. Without surgery, survival rates have been reported between $2-3$ years $(1,2)$.

Aortic valve replacement (AVR) improves life expectancy and symptoms of patients with hemodynamically significant aortic valve pathology, as well as the survival of asymptomatic patients with low left ventricular ejection fraction. Even if AVR is the first line of treatment for those patients, due to the changing features of this population, in the last 20 years, technology has evolved, and it is still continuously evolving to offer a resolutive treatment to this fragile population, while maintaining, at least, the previous results obtained with conventional surgical AVR and minimizing the risks due to the procedure itself $(3,4)$.

In fact, we observe an impressive increase and investment in this field, through the development of the transcatheter aortic valve implantation or replacement (TAVI or TAVR) approaches as well as new valvular prosthesis. TAVR has evolved from a procedure firstly indicated to only to high-risk patients, to a safe and effective procedure for intermediate- and low-risk patients. Even if surgical valve replacement remains the option of choice, the expanded 
indication also to low-risk patients could result in a widespread use TAVR. Actually, the therapeutic choice of aortic stenosis (AS) depends upon multiple factors and the final decision must be taken after the patient has been wellinformed about all therapeutic possibilities and the pros and cons (5).

In some cases, because of the anatomy, valve calcification etc., TAVR application might have limitations. For this reason, surgeons have developed and well stablished minimal invasive approaches for aortic valve replacement (MI-AVR), so reducing surgical trauma (6). Many clinical advantages and good outcomes of MI-AVR are continuously reported. It is of paramount importance to continue to expand the development of the technology for MI-AVR approaches, to keep surgical approaches relevant and ubiquitous.

Currently, both commonest approaches for MI-AVR are the upper hemisternotomy (UHS) and the right anterior minithoracotomy (RAT). However, MI-AVR it is still not widespread in the surgical community (7), due to the feeling of increase complexity of conventional surgery through a small incision.

Many efforts are continuously evolving to develop new technologies, like exposure devices, an increase adoption of rapid deployment and sutureless prosthesis or devices to facilitate the suture of the well-known stented valves, then lessening surgical challenges and making MI-AVR simple and reproducible while maintaining the many advantages of a minimally invasive operation.

Here, we present the case of MI-AVR of a stented conventional aortic valve prosthesis, using two new devices specifically designed to allow an easier sew and knot tie of the prosthesis in the aortic annulus. We present the following case in accordance with the CARE reporting checklist (available at https://jovs.amegroups.com/article/ view/10.21037/jovs-20-126/rc).

\section{Case presentation}

We present the case of a 65-year-old female without any particular comorbidity, with systemic blood hypertension and hypercholesterolemia.

Her history begun in 2008, when an aortic valve regurgitation was fortuitously found in a cardiologic and echographic check. Patient started to develop mild symptoms of dyspnea on 2009. She was on periodic cardiologic follow up. On august 2019, transthoracic echocardiogram showed a severe aortic regurgitation, with a maximum and medium transvalvular gradient of 46 and $29 \mathrm{mmHg}$ respectively. The valve was described for the first time as a bicuspid aortic valve, Sievers Class I (8). Ventricular parameters were preserved with ejection fraction of $67 \%$, left ventricular outflow tract of $1.8 \mathrm{~cm}$ and telediasuolic volume of $62 \mathrm{~mL}$. Ascending aorta had $3.2 \mathrm{~cm}$ of diameter. Patient was on functional NYHA II. After lady's informed interview and heart team discussion, patient was electively scheduled for AVR through minimal invasive approach.

All procedures performed in this study were in accordance with the ethical standards of the institutional and/or national research committee(s) and with the Helsinki Declaration (as revised in 2013). Written informed consent was obtained from the patient for publication of this case report and accompanying images. A copy of the written consent is available for review by the editorial office of this journal.

Surgery was performed through UHS, that is the "J" hemisternotomy toward the right IVth intercostal space, preserving the right internal mammary artery. After positioning the retrosternal drain and opening the pericardium, a tube for $\mathrm{CO} 2$ diffusion was put in place, systemic heparin delivered, and central cannulation of the ascending aorta and right atrial appendage achieved. Left ventricular venting tube was introduced trough the superior right pulmonary vein in the usual fashion, on full cardiopulmonary bypass, with filled left ventricle to avoid air input. After aortic cross clamping, transversal aortotomy was made, and Custodiol ${ }^{\circledR}$ (Modified Bretschneider Solution) was delivered selectively into the coronary ostia.

After exposure to the aortic valve, commissural sutures were placed, and the native valve was excised. In this particular case, minimal annular debridement of calcium was required. After sizing of the valve, we chose a pericardial tissue valve Edwards Magna Ease num 19.

Then we used the automated suturing device, which is composed by two elements, the RAM ${ }^{\circledR}$ and the SEWEASY $^{\circledR}$ devices (LSI SOLUTIONS ${ }^{\circledR}$, Victor, NY, USA). The $\mathrm{RAM}^{\circledR}$ device is an adjustable long-shafted, suturing device with two curved needles that places a horizontal mattress pledgeted 2-0 polyester suture in the sub annular position (Figure 1A). The proximal end of this device contains two rotational knobs that manipulate the device tip. One knob rotates the shaft in a 360-degree motion, and the other articulates the tip in a flexion/extension fashion. After positioning correctly, the device at the annular level, tissue was clung simultaneously with two curved needles in a fixed arc, by depressing the device lever. The lever was retracted, and needles went back into the device, through 


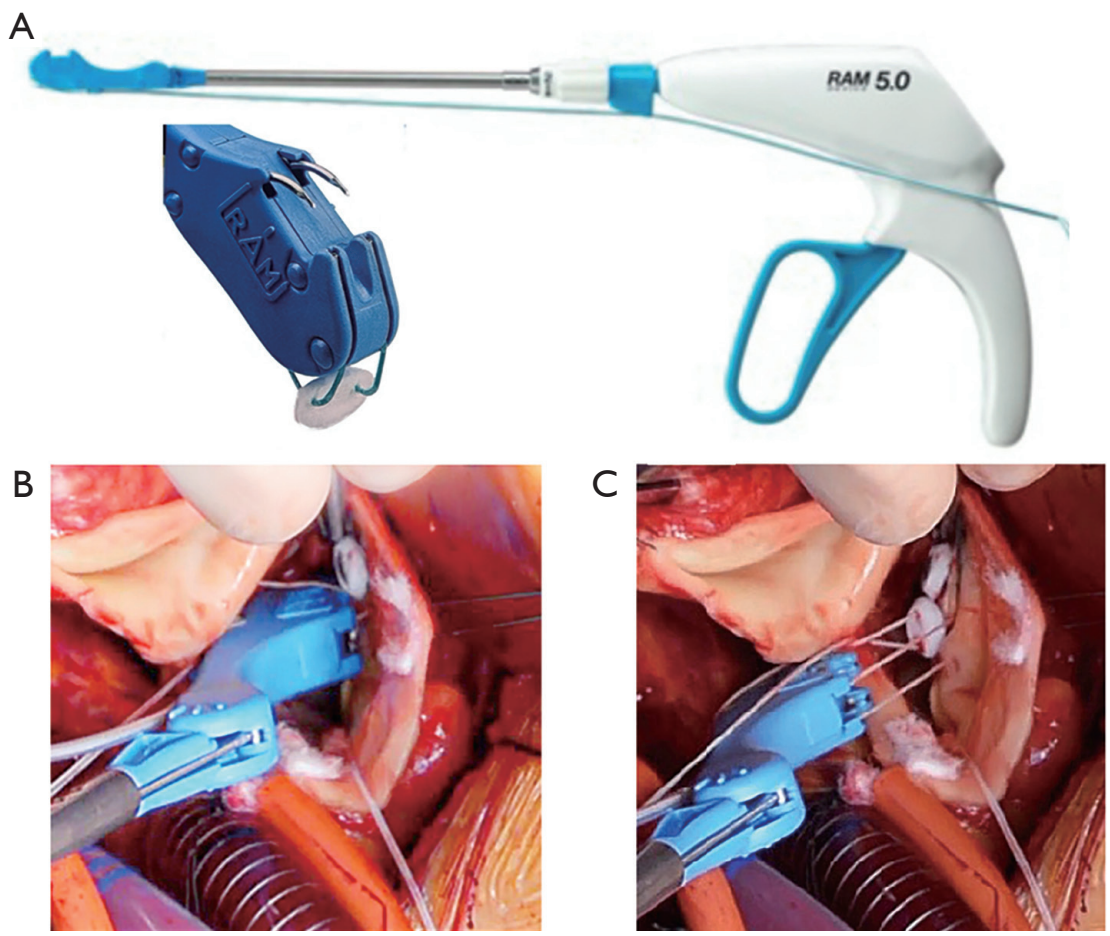

Figure 1 The first suturing device $\left(\mathrm{RAM}^{\circledR}\right)$ and the detail of the two curved needles are shown (A). The RAM ${ }^{\circledR}$ allows a symmetric and simultaneous positioning of pledgeted sutures in sub annular position (B). Then, suture is pulled forward (C).

tissue, bringing the suture loop and pledget with it, and seating the pledgeted in the desired position (Figure 1B); the suture ends were released automatically when the lever was pulled forward (Figure 1C). This process was repeated for every pair of sutures. The second device, the SEWEASY $^{\circledR}$ (Figure $2 A$ ) device is shafted with two straight needles that places the two ends of the horizontal mattress through the valve sewing cuff. The suture ends were loaded into the device. The sewing ring of the prosthesis was put in between the recess of the tip of the device. Two straight needles were simultaneously pushed into the cuff when the lever is depresses (Figure 2B). When they engaged the suture ends, the lever was released and the needles retracted back into the sheath, bringing the suture through the sewing cuff; the suture was then removed from the device. The prosthetic valve was seated. Sutures were tied using the COR-KNOT $^{\circledR}$ (LSI SOLUTIONS, Victor, NY, USA) (Figure $3 A, 3 B$ ), a knotting device which is a crimped medical grade titanium hollow sleeve. The remainder of the case concluded in a routine fashion. All the surgical procedure is well demonstrated in the video (Video 1). Postoperative outcome was uneventful, and patients were discharged in fifth postoperative day. After almost 1 year of follow up the patient is on NYHA Class I and all clinical and instrumental evaluation demonstrate normal functioning of the prosthesis without any pathological finding.

\section{Discussion}

Valvular heart disease is a relevant health problem worldwide, with a significant impact on healthcare system. Furthermore, these pathologies particularly hit an elderly and sick population due to the increase of life expectancy (9). The treatment of aortic valve disease has also evolved in a manner which cardiac surgeons and cardiologists would have never figured out, since the first reported treatment of AS in 1960 (10). TAVR is now considered the first therapeutic option for the very sick patients. Now, it is also contemplated as a good option for the intermediate- and low-risk groups due to the non-inferiority demonstrated results. However, its Achille's heel, compared with the surgical approach, it is the inability of aortic valve resection neither annular decalcification, leading to a significant incidence of paravalvular leak (PVL), permanent pacemaker implantation (PPI), stroke and reduced longterm survival $(11,12)$. There are also several anatomic and 

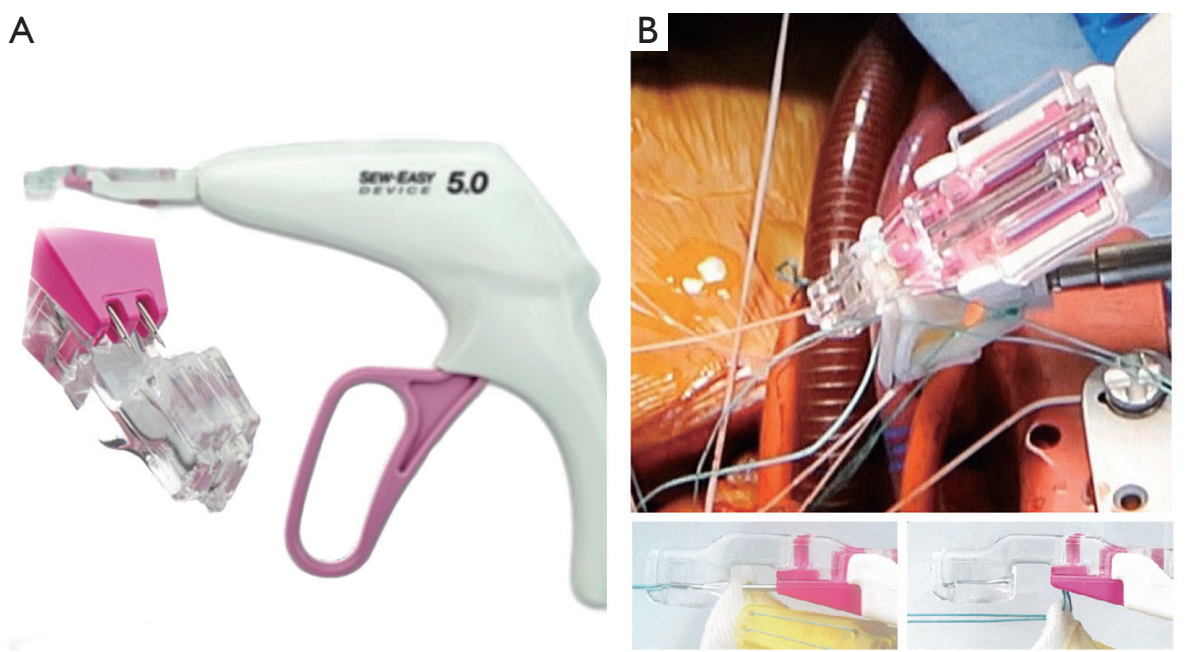

Figure 2 With the second device, the SEW-EASY ${ }^{\circledR}(\mathrm{A})$, sutures are placed in the sewing cuff of the prosthesis (B).
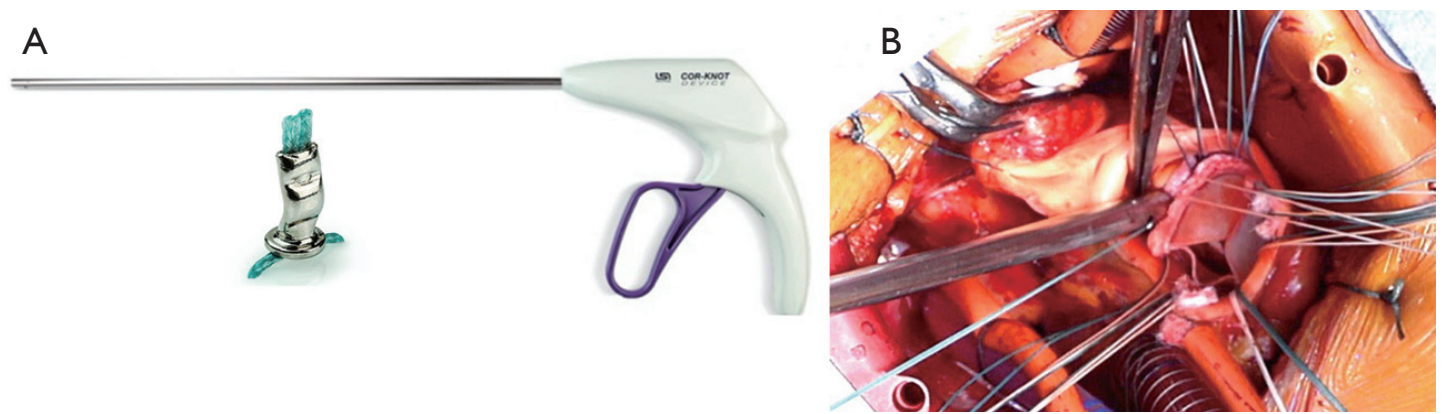

Figure 3 The COR-KNOT ${ }^{\circledR}$ (A), is the knotting system. By pushing the proximal tip of the device (B), the titanium hollows are crimped, and suture fixed.

vascular related problems that might preclude transcatheter intervention (13). Despite evolving tendency of cardiac surgery, with the decline of sternotomy-based surgical AVR numbers and with TAVR becoming almost the first choice for structural repair, the surgical community move toward minimally invasive surgical accesses, introducing new tools in order to improve patients' outcomes and to make surgery appealing and competitive in terms of results and invasiveness.

MI-AVR could matches advantages of the convention AVR approach, with the demonstrated and several advantages of minimal invasive approach. Avoiding full sternotomy and its related morbidities, has particularly remarkable benefits in elderly population. In a study evaluating minimally invasive valve surgery versus median sternotomy in patients 75 years or older, those having a minimally invasive approach were found to have significantly lower associated morbidity and mortality (4). In addition, minimally invasive cardiac surgery (MICS) is associated with reduced length of stay, in-hospital as well as in intensive care unit (ICU), less time of intubation, less infections, incidence of atrial fibrillation as well as blood loss and transfusions, resulting in an overall health costs benefit (14). The less the surgical trauma, less the pain and faster the recovery are, considering also the cosmetic plus.

Nonetheless, MI-AVR has been used for more than 20 years and despite the steadily increased case volume over the last 10 years, it is still not the preferred approach being used in a low proportion of patients. Procedural and technological improvements in MI-AVR, would maintain the growth of surgical AVR for AS patients.

Regarding new prosthesis, many series and registries have demonstrated $(14,15)$ the safety and the reliability of sutureless and rapid deployment prosthesis, compared with 


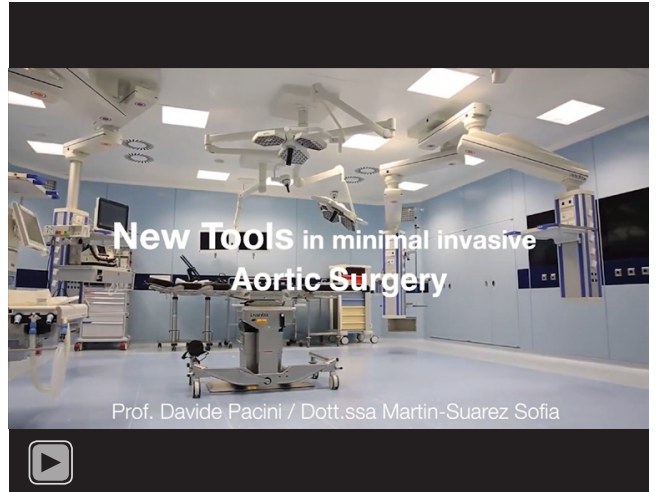

Video 1 This is a standard case of aortic valve regurgitation of a 65 years old female, with known disease since 2008 and symptomatic in functional class II. At the echo valved looked bicuspid. The operations scheduled was aortic valve replacement with a tissue valve (actually was a CE num 19) through a J sternotomy. An innovative device composed of two staples, called RAM ${ }^{\circledR}$ and the other SEW-EASY ${ }^{\circledR}$, was intended to use for suturing the prosthesis. Also, the use of another well-known device, aimed to tied suture, called COR-KNOT ${ }^{\circledR}$ was established. After central cannulation and selective delivery of cardioplegia, aortic cusps are resected. With the RAM $^{\circledR}$ device the two ends of the tread with the Teflon pledget are passed equidistant in the aortic annulus, after previous loading of the stitch into the device. Then, with the called SEW-EASY ${ }^{\circledR}$ device, stitches are also symmetrically passed through the sewing ring of the prosthesis. After the prosthesis is parachuted, the COR-KNOT ${ }^{\circledR}$ device was used to finally tie the stitches. The intraoperative echo showed well positioned prosthesis, without paravalvular leak.

TAVR in terms of procedural mortality, PPI, as well as PVL which is demonstrated to negatively affect the survival (16).

These prostheses have been developed to radically simplify surgery overcoming surgical exposure drawbacks during suture positioning and knotting, with inherent benefits for the patients (14-16). Also, the use of new sutureless prosthesis in MICS reduces times of cardiopulmonary bypass and crossclamping as reported by other previous experience and data reported from STS registry (4).

The main criticism of these new prosthesis is the deficiency of data describing the long-term durability and hemodynamic performances. The use of newer generation prostheses, either in the AVR, MI-AVR or TAVI, although attractive for their ease of implantation, potentially carries higher long-term risk due to shorter durability leading to reintervention to address valve deterioration. This is especially true in low-risk patients who are younger and still active. These patients are likely better served with the timetested prostheses with well-known durability and freedom from structural deterioration (17).

Preclinical and clinical studies have evaluated new sewing devices to be used on minimally invasive cardiac procedures. The first early clinical report of the feasibility of novel automated suturing technology developed for this purpose was reported by Wong et al. in 2018 (18). Devices used in 5 MI-AVR patients through RAT, were RAM ${ }^{\circledR}$, SEW-EASY ${ }^{\circledR}$ and COR-KNOT ${ }^{\circledR}$, devices (LSI SOLUTIONS ${ }^{\circledR}$, Victor, NY, USA) as in our present case. Same group reported the use of these device in another cohort of 12 patients, undergoing MI-AVR requiring annular enlargement (19). They conclude that these suturing and knotting devices could be a useful adjunct to the surgeon during MI-AVRs by reducing the technical "conflicts" due to the confined surgical space.

In the present video, we've shown the feasibility, reproducibility and utility of these device. Off course the present case referrers of a single case and even if the it demonstrated the value of this devise, a bigger cohort is needed to encourage its routine employment.

\section{Conclusions}

We agree with other authors (20) that the management of aortic valve pathology will predominately involve minimally invasive and endovascular techniques. For many reasons, surgery will continue to play a major role for these patients and since the minimal invasive surgery has proven multiple benefits, cardiac surgeon must develop, not only a new mental approach, also new skills and embrace new tools thanks to the prolific technology, to become more proficient in that field. As take-home message we would like the present case to suppose a stimulus for the community of cardiac surgeons to the routine practice of the mini-invasive approaches thanks also to the constant improvement of available technologies.

\section{Acknowledgments}

Funding: The video has been sponsored by LeviBio Medical Srl.

\section{Footnote}

Provenance and Peer Review: This article was commissioned 
by the editorial office, Fournal of Visualized Surgery for the series "Best Video Presentation Prize for the 10th Postgraduate Course on 'Surgery of the Thoracic Aorta' in Bologna". The article has undergone external peer review.

Reporting Checklist: The authors have completed the CARE reporting checklist. Available at https://jovs.amegroups. com/article/view/10.21037/jovs-20-126/rc

Conflicts of Interest: All authors have completed the ICMJE uniform disclosure form (available at https://jovs. amegroups.com/article/view/10.21037/jovs-20-126/coif). The series "Best Video Presentation Prize for the 10th Postgraduate Course on 'Surgery of the Thoracic Aorta' in Bologna" was commissioned by the editorial office without any funding or sponsorship. DP served as the unpaid Guest Editor of the series. The authors have no other conflicts of interest to declare.

Ethical Statement: The authors are accountable for all aspects of the work in ensuring that questions related to the accuracy or integrity of any part of the work are appropriately investigated and resolved. All procedures performed in this study were in accordance with the ethical standards of the institutional and/or national research committee(s) and with the Helsinki Declaration (as revised in 2013). Written informed consent was obtained from the patient for publication of this case report and accompanying images. A copy of the written consent is available for review by the editorial office of this journal.

Open Access Statement: This is an Open Access article distributed in accordance with the Creative Commons Attribution-NonCommercial-NoDerivs 4.0 International License (CC BY-NC-ND 4.0), which permits the noncommercial replication and distribution of the article with the strict proviso that no changes or edits are made and the original work is properly cited (including links to both the formal publication through the relevant DOI and the license). See: https://creativecommons.org/licenses/by-nc-nd/4.0/.

\section{References}

1. Maganti K, Rigolin VH, Sarano ME, et al. Valvular heart disease: diagnosis and management. Mayo Clin Proc 2010;85:483-500.

2. Horstkotte D, Loogen F. The natural history of aortic valve stenosis. Eur Heart J 1988;9 Suppl E:57-64.
3. Cohn LH, Adams DH, Couper GS, et al. Minimally invasive cardiac valve surgery improves patient satisfaction while reducing costs of cardiac valve replacement and repair. Ann Surg 1997;226:421-6; discussion 427-8.

4. Lamelas J, Sarria A, Santana O, et al. Outcomes of minimally invasive valve surgery versus median sternotomy in patients age 75 years or greater. Ann Thorac Surg 2011;91:79-84.

5. Nishimura RA, Otto CM, Bonow RO, et al. 2017 AHA/ ACC focused update of the 2014 AHA/ACC guideline for the management of patients with valvular heart disease: a report of the American College of Cardiology/American Heart Association Task Force on Clinical Practice Guidelines. Circulation 2017;135:e1159-95.

6. Cosgrove DM 3rd, Sabik JF. Minimally invasive approach for aortic valve operations. Ann Thorac Surg 1996;62:596-7.

7. O'Brien SM, Shahian DM, Filardo G, et al. The Society of Thoracic Surgeons 2008 cardiac surgery risk models: part 2--isolated valve surgery. Ann Thorac Surg 2009;88:S23-42.

8. Sievers HH, Schmidtke C. A classification system for the bicuspid aortic valve from 304 surgical specimens. J Thorac Cardiovasc Surg 2007;133:1226-33.

9. Coffey S, Cairns BJ, Iung B. The modern epidemiology of heart valve disease. Heart 2016;102:75-85.

10. Harken DE, Taylor WJ, Lefemine AA, et al. Aortic valve replacement with a caged ball valve. Am J Cardiol 1962;9:292-9.

11. Pollari F, Dell'Aquila AM, Söhn C, et al. Risk factors for paravalvular leak after transcatheter aortic valve replacement. J Thorac Cardiovasc Surg 2019;157:1406-15.e3.

12. Pollari F, Hitzl W, Vogt F, et al. Aortic valve calcification as a risk factor for major complications and reduced survival after transcatheter replacement. J Cardiovasc Comput Tomogr 2020;14:307-13.

13. Ielasi A, Latib A, Tespili M, et al. Current results and remaining challenges of trans-catheter aortic valve replacement expansion in intermediate and low risk patients. Int J Cardiol Heart Vasc 2019;23:100375.

14. Glauber M, Di Bacco L, Cuenca J, et al. Minimally invasive aortic valve replacement with sutureless valves: results from an international prospective registry. Innovations (Phila) 2020;15:120-30.

15. Di Eusanio M, Phan K, Berretta P, et al. Sutureless and Rapid-Deployment Aortic Valve Replacement International Registry (SURD-IR): early results from 3343 patients. Eur J Cardiothorac Surg 2018;54:768-73.

16. Leon MB, Smith CR, Mack MJ, et al. Transcatheter or 
surgical aortic-valve replacement in intermediate-risk patients. N Engl J Med 2016;374:1609-20.

17. Cinelli M, Schwartz L, Spagnola J, et al. Early structural deterioration of a sutureless bioprosthetic aortic valve. Cardiol Res 2020;11:113-7.

18. Wong JK, Melvin AL, Siordia JA, et al. Novel automated suturing technology for minimally invasive aortic valve

doi: 10.21037 /jovs-20-126

Cite this article as: Martin-Suarez S, Mariani C, Murana G, Berardi M, Agulli M, Carlo S, Pacini D. New tools in minimal invasive aortic valve surgery: case report. J Vis Surg 2022;8:29. replacements. Ann Thorac Surg 2018;105:645-9.

19. Robinson DA, Johnson CA Jr, Goodman AM, et al. Concomitant annular enlargement in minimally invasive aortic valve replacement. Innovations (Phila) 2019;14:159-67.

20. Lamelas J, Alnajar A. Recent advances in devices for minimally invasive aortic valve replacement. Expert Rev Med Devices 2020;17:201-8. 